\title{
Erratum: Unexpected failure rates for modular assembly of engineered zinc fingers
}

Cherie L Ramirez, Jonathan E Foley, David A Wright, Felix Müller-Lerch, Shamim H Rahman, Tatjana I Cornu, Ronnie J Winfrey, Jeffry D Sander, Fengli Fu, Jeffrey A Townsend, Toni Cathomen, Daniel F Voytas \& J Keith Joung

Nat. Methods 5, 374-375 (2008); corrected after print 29 May 2008.

In the version of this correspondence initially published, the two previously published datasets analyzed were labeled with incorrect references in Figure 1b. Reference 2 should be associated with the second column ( 80 sites), and reference 3 should be associated with the third column (96 sites).

The weblink for the Zinc Finger Consortium website was incorrect and should be http://www.zincfingers.org/.

The errors have been corrected in the HTML and PDF versions of the article.

\section{Erratum: SNP genotyping: six technologies that keyed a revolution}

\section{Jeffrey Perkel}

Nat. Methods 5, 447-453 (2008).

In the "Battle of the chips" section, the Infinium assay from Illumina was misspelled. 